\title{
The Cost of Initial Care for Medicare Patients With Advanced Ovarian Cancer
}

\author{
Renata R. Urban, MD' ; Hao He, $\mathrm{PhD}^{\mathrm{b}}$; Rafael Alfonso-Cristancho, $\mathrm{MD}, \mathrm{PhD}^{\mathrm{b}}$; \\ Melissa M. Hardesty, MD, MPH'; and Barbara A. Goff, MDa
}

\begin{abstract}
Objectives: In preparation for payment reform, we evaluated Medicare payments for the initial treatment of patients with advanced ovarian cancer and assessed factors responsible for variation. Methods: Using the linked SEER-Medicare database, we identified a cohort of 9,491 women aged 65 years or older with stage III/IV epithelial ovarian cancer diagnosed between 1995 and 2007 . Diagnostic and procedural codes specific to the care of ovarian cancer were used to estimate total medical costs for the treatment of ovarian cancer. Costs were adjusted for geography and for inflation to the 2009 US dollar. NCCN Guideline-consistent care was defined as surgery and 6 cycles of chemotherapy. A generalized linear regression was performed to assess factors associated with variability in cost. Results: The mean total payment per patient in the initial treatment period was $\$ 65,908$ (range of means, $\$ 30,745-\$ 96,360$ ). Increasing medical comorbidity, use of $\mathrm{PET} / \mathrm{CT}$, surgical complications, and readmissions were associated with increased costs. Treatment with NCCN Guideline-consistent surgery and chemotherapy had a mean annual cost of $\$ 85,987$ compared with $\$ 89,149$ for non-NCCN Guideline-consistent treatment with surgery and chemotherapy. The cost of surgery and chemotherapy that was not consistent with NCCN Guidelines was approximately $\$ 7,000$ more than the cost of therapy that was consistent $(P<.001)$ Conclusions: The financial burden of caring for patients with ovarian cancer is substantial. Treatment that is consistent with NCCN recommendations for treating advanced ovarian cancer, which is shown to have improved outcomes, is not associated with higher cost.
\end{abstract}

J Natl Compr Canc Netw 2016;14(4):429-437

\section{Background}

As medical costs continue to increase, it is important to focus on new therapies and how existing therapies are applied in order to identify areas of waste and inefficiency. For patients with cancer, this will be challenging, because medical costs are projected to continue to increase. ${ }^{1}$ Because physicians play a substantial role in maintaining the quality of care and cost containment, it is crucial that each specialty take part in assessing costs pertaining to the diseases that they treat.

In preparation for payment reform, ASCO developed a bundled payment model for the treatment of patients with cancer using chemotherapy. ${ }^{2,3}$ Ovarian cancer is a complex disease requiring surgery and chemotherapy to achieve the best outcomes, which in-

From the aDivision of Gynecologic Oncology, Department of Obstetrics and Gynecology, and 'Surgical Outcomes Research Center, University of Washington, Seattle, Washington; and 'Alaska Women's Cancer Care, Anchorage, Alaska.

Submitted September 30, 2015; accepted for publication February 17, 2016.

The authors have disclosed that they have no financial interests, arrangements, affiliations, or commercial interests with the manufacturers of any products discussed in this article or their competitors. volves gynecologic and medical oncologists. ${ }^{4}$ There are high rates of complications associated with these therapies, which can impact the cost of care. This may produce unique opportunities for a disease-based payment system. The importance of assessing the baseline costs of care for patients with ovarian cancer will be crucial in assessing the cost-effectiveness of treatment interventions and payment strategies. ${ }^{5}$

Prior studies documenting the costs of care for patients with ovarian cancer have either used a brief period of time, or have described costs for a particular treatment type. ${ }^{6-8}$ Our objectives were to use the SEER-Medicare data set to describe the costs of care for patients with ovarian cancer in the first year after diagnosis, evaluate differences in costs depending on treatment approach, and evaluate factors responsible for variation.

This study was accepted as a poster at the Society of Gynecologic Oncologists Annual Meeting in Chicago, IL, on March 22-24, 2015, and at the Western Association of Gynecologic Oncologists Annual Meeting in Santa Rosa, CA, June 10-13, 2015.

Correspondence: Renata R. Urban, MD, Department of Obstetrics \& Gynecology, University of Washington Medical Center, 1959 NE Pacific Street, Campus Box 356460, Seattle, WA 98195-6460.

E-mail: urbanr@u.washington.edu 
Urban et al

\section{Methods}

\section{Data Source}

Institutional Review Board approval for this study was obtained by the Fred Hutchison Cancer Research Consortium (FHCRC\# 9270). This was a retrospective, population-based study using the linked SEER-Medicare database, which consists of data from the SEER registry provided by the NCI linked to patient records in the Medicare claims records provided by the Centers for Medicare \& Medicaid Services (CMS). The SEER database is composed of records from national cancer registries that served $14 \%$ of the US population in 1995 and 26\% in 2004; approximately $97 \%$ of incident cancer cases in these areas are included in SEER. For patients older than 65 years in the SEER database, 93\% have been able to be identified in the Medicare enrollment file and have their records successfully matched to SEER records in the linkage process. ${ }^{9}$

\section{Cohort Selection, Patient Characteristics, and Treatment Identification}

This study identified all women older than 65 years diagnosed with ovarian cancer $(n=26,379)$ in SEER cancer registries from January 1, 1995, to December 31,2007 . Women were excluded if they had a diagnosis based on autopsy or death certificate only $(n=784)$; nonepithelial malignancies; borderline or noninvasive pathology $(n=1,384)$; prior malignancies before or after the ovarian cancer diagnosis $(n=3,647)$; or stage I, II, or unknown disease $(n=3,980)$. Women were excluded if they did not have continuous eligible Medicare coverage (Part A and $\mathrm{B}$ without $\mathrm{HMO}$ ) for at least 3 months before the date of diagnosis $(n=4,162)$ and for at least 12 months after the date of diagnosis $(n=2,937)$. We restricted the cohort to patients with AJCC stage III or IV ovarian cancer. Patients classified as AJCC unstaged in SEER, but who were classified as advanced disease, were also included. All patients in this cohort were followed through December 2008 until the end of data or death.

Demographic characteristics included age at diagnosis, race, sex, geographic location, and marital status. Clinical variables included stage, grade, and histology. Comorbidities were assessed using claims for the 6 months before diagnosis to calculate the Deyo adaptation $^{10}$ of the Charlson comorbidity index. ${ }^{11}$

\section{Outcomes}

Medicare claims data were used to identify treatments; claims with a diagnosis code for ovarian cancer (183.0) were included as our outcome of interest. Receipt of chemotherapy was identified if either the inpatient record, outpatient file, or physician claims indicated that chemotherapy was given within 12 months after the cancer diagnosis (see supplemental eAppendix 1, available with this article at JNCCN.org). Chemotherapy claims were grouped into "weeks of received therapy" according to the dates of the claims; this was used to designate cycles of chemotherapy, as has been done previously. ${ }^{11,12}$ Surgical treatment was identified in the MEDPAR (Medicare Provider Analysis and Review) files using International Classification of Diseases, Ninth Revision (ICD-9) procedural codes, and in the physician claims using Current Procedural Terminology (CPT) codes, indicating surgical procedures consistent with surgery for ovarian cancer (eAppendix 1). Postoperative complications were defined as previously described $^{13}$ and included medical and surgical complications occurring within 30 days of the index surgery. Reoperations were defined as a claim for surgical treatment occurring within 30 days of the index surgery.

Patients classified as receiving surgery followed by chemotherapy represented patients with a diagnosis of ovarian cancer and claims for surgery, without any claims for chemotherapy in between the diagnosis and surgery. Patients classified as receiving neoadjuvant chemotherapy consisted of those who had any claim for chemotherapy after a diagnosis of ovarian cancer and preceding claims for a surgical procedure for cancer. We also classified treatment as whether it was consistent with the treatment recommendations in the NCCN Clinical Practice Guidelines in Oncology (NCCN Guidelines) for Ovarian Cancer. ${ }^{14,15}$ The current therapy recommended by NCCN for the optimal therapy of advanced epithelial ovarian cancer consists of surgery and 6 to 8 cycles of chemotherapy; the sequence of therapy can consist of either surgery followed by chemotherapy, or neoadjuvant chemotherapy with interval surgery and adjuvant chemotherapy. Similar to prior analyses, ${ }^{12}$ patients were designated as having had "NCCN Guideline-consistent" therapy if they had surgical treatment and at least 6 cycles of chemotherapy. Patients who had surgery and chemotherapy who did not meet this requirement were designated as having had "non-NCCN Guideline-consistent" therapy. 
Total medical costs were estimated from Medicare facility and provider claims, and adjusted for inflation and geography. ${ }^{15}$ In this analysis, cost refers to the amount reimbursed by Medicare. Because 2009 was the most recent year for which we had Medicare reimbursements records, all cost were converted in terms of 2009 dollars according to the claim services time. For inpatient facility costs (Medicare Part A), inflation was adjusted by CMS Inpatient Prospective Payment System. ${ }^{16}$ Index and geography was adjusted by 2009 CMS geographic adjustment factor ${ }^{17}$; for outpatient facility costs and carrier/physician/supplier costs (Medicare Part B), inflation was adjusted by the Medicare Economic Index ${ }^{18}$ and geography was adjusted by the 2009 CMS geographic practice cost index. ${ }^{19}$

\section{Statistical Analysis}

In the unadjusted analyses, $\chi^{2}$ tests were used to assess the associations between initial treatment type and demographic and clinical factors. The distribution of total cost was slightly right-skewed, indicating a potential violation to the normal distribution assumption of cost. In the multivariate adjusted analyses for cost, the general linear model, log-linear model, and generalized linear model with gamma distribution assumption were explored and compared. Because the results from all models were similar, the general linear regression was adopted to assess factors associated with variability in cost. The linear regression was applied to the entire cohort; in addition, given that previous studies have shown that surgical complications and readmissions are associated with increased cost of care, we performed a subsequent linear regression for only those patients who had surgery as part of their treatment. All analyses in this study were conducted at a server environment using SAS 9.3 software (SAS Institute Inc., Cary, NC).

\section{Results}

Of the 9,491 patients with stage III/IV ovarian cancer identified from 1995 to 2007, at the time of diagnosis 7,064 (74.4\%) were between 65 and 80 years of age and 3,233 (34.1\%) were 80 years or older. Demographic, clinical, and pathologic characteristics of these groups are shown in Table 1 . A total of 2,902 patients $(30.6 \%)$ were treated with surgery followed by chemotherapy, $940(9.9 \%)$ received neoadjuvant chemotherapy followed by surgery, 2,597 (27.4\%) had chemotherapy alone, 734 (7.7\%) had surgery alone, and 2,318 (24.4\%) did not receive any treatment. For all patients who received both surgery and chemotherapy, only $9.8 \%$ did not receive a platinum nor a taxane. Of the 940 patients who received neoadjuvant chemotherapy $771(82.0 \%)$ received more than 6 cycles of chemotherapy compared with 1,888 (65.0\%) of those who had primary surgery followed by chemotherapy $(P<.001)$.

We then categorized patients who received both surgery and chemotherapy according to whether therapy was consistent with NCCN Guidelines: 2,689 patients (28\%) received NCCN Guideline-consistent surgery and chemotherapy and 1,183 (12.5\%) received non-NCCN Guideline-consistent surgery and chemotherapy. Over the past 12 years, the percentage of women who received NCCN Guidelineconsistent therapy was noted to increase $(P<.0001)$. The proportion of women who did not receive treatment remained stable $(P=.3124)$ (Figure 1$)$.

The mean total adjusted payments per patient in the initial treatment period were $\$ 65,908$ (range of means, $\$ 30,645-\$ 96,360)$. Initial treatment costs were divided relatively equally between inpatient and outpatient costs (Table 2). The mean inpatient cost per patient over this period was $\$ 35,992$; this included payments for surgery and postoperative care. The average payment related to surgery during the period was $\$ 8,575$. The mean outpatient cost per patient over this period was $\$ 29,915$; nearly one-third of these payments were related to chemotherapy (Table 3). The median cost of NCCN Guidelineconsistent treatment was $\$ 85,987$. In comparison, non-NCCN Guideline-consistent treatment with surgery and chemotherapy was $\$ 89,148$.

On multivariate analysis for the entire cohort, age, year at diagnosis, race, education, region, area, comorbidity, and treatment type were associated with variation in cost. Increased medical comorbidity, residence in the West and metropolitan areas, and use of PET/CT scan were associated with significantly increased costs. Surgical complications and readmissions were associated with significantly increased cost after adjustment for other pertinent factors. The cost of neoadjuvant chemotherapy was still $\$ 14,390$ more than surgery and chemotherapy after adjusting for all significant factors, including medical comorbidity, surgical complications, and readmissions $(P<.001)$. 
Urban et al

Table 1. Demographic and Clinical Characteristics

\begin{tabular}{|c|c|c|c|c|c|c|c|}
\hline \multirow[b]{2}{*}{ Characteristic } & \multirow[b]{2}{*}{$\begin{array}{l}N \\
(\%)\end{array}$} & \multicolumn{5}{|c|}{$\begin{array}{c}\text { Treatment Type } \\
(\%)\end{array}$} & \multirow[b]{2}{*}{$P$ Value } \\
\hline & & $\begin{array}{l}\text { No Treatment } \\
\text { (\%) }\end{array}$ & $\begin{array}{l}\text { Surgery } \\
\text { Onl } \\
(\%)\end{array}$ & $\begin{array}{l}\text { Chemotherapy } \\
\text { Only } \\
\text { (\%) }\end{array}$ & $\begin{array}{l}\text { Non-NCCN } \\
\text { Guidelines- } \\
\text { Consistent } \\
\text { Surgery and } \\
\text { Chemotherapy } \\
\text { (\%) }\end{array}$ & $\begin{array}{l}\text { NCCN } \\
\text { Guidelines- } \\
\text { Consistent } \\
\text { Surgery and } \\
\text { Chemotherapy } \\
\text { (\%) }\end{array}$ & \\
\hline & 9,491 & $2,318(24.4)$ & $734(7.7)$ & $2,597(27.4)$ & $1,183(12.5)$ & $2,659(28.0)$ & \\
\hline Year of diagnosis & & & & & & & $<.0001$ \\
\hline 1995-1998 & $1,986(20.9)$ & $469(20.2)$ & $186(25.3)$ & $516(19.9)$ & $369(31.2)$ & $446(16.8)$ & \\
\hline 1999-2001 & 2,365 (24.9) & $601(25.9)$ & $196(26.7)$ & $645(24.8)$ & $270(22.8)$ & $653(24.6)$ & \\
\hline $2002-2004$ & $2,713(28.6)$ & $640(27.6)$ & $191(26.0)$ & $774(29.8)$ & $253(21.4)$ & $855(32.2)$ & \\
\hline $2005-2007$ & $2,427(25.6)$ & $608(26.2)$ & $161(21.9)$ & $662(25.5)$ & $291(24.6)$ & $705(26.5)$ & \\
\hline Age at diagnosis, $y$ & & & & & & & $<.0001$ \\
\hline $65-69$ & 1,782 (18.8) & $202(8.7)$ & 87 (11.9) & $474(18.3)$ & $274(23.2)$ & $745(28.0)$ & \\
\hline $70-74$ & $2,244(23.6)$ & $296(12.8)$ & $134(18.3)$ & $662(25.5)$ & $322(27.2)$ & $830(31.2)$ & \\
\hline $75-79$ & $2,232(23.5)$ & $429(18.5)$ & $178(24.3)$ & $616(23.7)$ & $325(27.5)$ & $684(25.7)$ & \\
\hline$\geq 80$ & $3,233(34.1)$ & $1,391(60.0)$ & $335(45.6)$ & $845(32.5)$ & $262(22.2)$ & $400(15.0)$ & \\
\hline Race & & & & & & & $<.0001$ \\
\hline White & $8,400(88.5)$ & $1,988(85.8)$ & $645(87.9)$ & $2,303(88.7)$ & $1,042(88.1)$ & $2,422(91.1)$ & \\
\hline Black & $579(6.1)$ & $197(8.5)$ & $47(6.4)$ & $166(6.4)$ & $64(5.4)$ & $105(4.0)$ & \\
\hline Other/unknown & $512(5.4)$ & $133(5.7)$ & $42(5.7)$ & $128(4.9)$ & $77(6.5)$ & $132(5.0)$ & \\
\hline Marital status & & & & & & & $<.0001$ \\
\hline Married at diagnosis & $3,874(40.8)$ & $580(25.0)$ & $231(31.5)$ & $1,082(41.7)$ & $543(45.9)$ & $1,438(54.1)$ & \\
\hline Others & $5,617(59.2)$ & $1,738(75.0)$ & $503(68.5)$ & $1,515(58.3)$ & $640(54.1)$ & $1,221(45.9)$ & \\
\hline Income (median income c & of census trac & & & & & & $<.0001$ \\
\hline $\begin{array}{l}\text { Low ( } \leq 25 \% \text { quartile } \\
\text { of the medium } \\
\text { income ) }\end{array}$ & $2,350(26.4)$ & $672(31.0)$ & $201(29.8)$ & $640(26.1)$ & $277(25.8)$ & $560(22.0)$ & \\
\hline $\begin{array}{l}\text { Middle ( } 25 \%-75 \% \\
\text { quartiles) }\end{array}$ & 4,447 (49.9) & $1,081(49.8)$ & $339(50.2)$ & $1,222(49.8)$ & $524(48.8)$ & $1,281(50.4)$ & \\
\hline High ( $\geq 75 \%$ quartile) & $2,116(23.7)$ & $416(19.2)$ & $135(20.0)$ & $592(24.1)$ & $272(25.4)$ & $701(27.6)$ & \\
\hline Poverty (census tract $\%$ & at poverty lev & & & & & & $<.0001$ \\
\hline $\begin{array}{l}\text { High ( } \geq 75 \% \text { quartile } \\
\text { of the poverty rate ) }\end{array}$ & $2,111(23.7)$ & $620(28.6)$ & $172(25.5)$ & $582(23.7)$ & $256(23.9)$ & $481(18.9)$ & \\
\hline $\begin{array}{l}\text { Middle ( } 25 \%-75 \% \\
\text { quartiles) }\end{array}$ & $4,415(49.5)$ & $1,063(49.0)$ & $331(49.0)$ & $1,193(48.6)$ & $530(49.4)$ & $1,298(51.1)$ & \\
\hline $\begin{array}{l}\text { Low ( } \leq 25 \% \text { quartile } \\
\text { of the poverty rate) }\end{array}$ & $2,387(26.8)$ & $486(22.4)$ & $172(25.5)$ & $679(27.7)$ & $287(26.8)$ & $763(30.0)$ & \\
\hline Education (census tract $\%$ & $\%$ of non-high & school graduat & & & & & $<.0001$ \\
\hline Low ( $\geq 75 \%$ quartile) & $2,025(22.7)$ & $600(27.7)$ & $164(24.3)$ & $565(23.0)$ & $237(22.1)$ & $459(18.1)$ & \\
\hline $\begin{array}{l}\text { Middle ( } 25 \%-75 \% \\
\text { quartiles) }\end{array}$ & $4,617(51.8)$ & $1,132(52.2)$ & $361(53.5)$ & $1,278(52.1)$ & 557 (51.9) & $1,289(50.7)$ & \\
\hline $\begin{array}{l}\text { High }(\leq 25 \% \\
\text { quartile) }\end{array}$ & $2,271(25.5)$ & $437(20.2)$ & $150(22.2)$ & $611(24.9)$ & $279(26.0)$ & 794 (31.2) & \\
\hline
\end{tabular}

Abbreviation: NA, not available.

aCharlson comorbidity index calculated based on diagnosis claims made 12 months before and during the index month of diagnosis.

bee supplemental eAppendix 1 for definitions of major and minor complications.

When we assessed the entire cohort and adjusted for all significant factors, the mean total costs of non-NCCN Guideline-consistent surgery and chemotherapy was found to be $\$ 7,564$ greater than the mean total costs of treatment with NCCN Guideline-consistent surgery and chemotherapy. We repeated the linear regression analysis of cost for only those patients who had surgery performed as part of 


\begin{tabular}{|c|c|c|c|c|c|c|c|}
\hline \multirow[b]{2}{*}{ Characteristic } & \multirow[b]{2}{*}{$\begin{array}{l}N \\
(\%)\end{array}$} & \multicolumn{5}{|c|}{$\begin{array}{c}\text { Treatment Type } \\
(\%)\end{array}$} & \multirow[b]{2}{*}{$P$ Value } \\
\hline & & $\begin{array}{l}\text { No Treatment } \\
(\%)\end{array}$ & $\begin{array}{l}\text { Surgery } \\
\text { Onl } \\
(\%)\end{array}$ & $\begin{array}{l}\text { Chemotherapy } \\
\text { Only } \\
(\%)\end{array}$ & $\begin{array}{l}\text { Non-NCCN } \\
\text { Guidelines- } \\
\text { Consistent } \\
\text { Surgery and } \\
\text { Chemotherapy } \\
(\%)\end{array}$ & $\begin{array}{l}\text { NCCN } \\
\text { Guidelines- } \\
\text { Consistent } \\
\text { Surgery and } \\
\text { Chemotherapy } \\
(\%)\end{array}$ & \\
\hline Region & & & & & & & $<.0001$ \\
\hline Northeast & $1,946(20.5)$ & $469(20.2)$ & $144(19.6)$ & $558(21.5)$ & $206(17.4)$ & $569(21.4)$ & \\
\hline Midwest & $1,722(18.1)$ & $463(20.0)$ & $154(21.0)$ & $458(17.6)$ & $234(19.8)$ & $413(15.5)$ & \\
\hline South & $1,483(15.6)$ & $367(15.8)$ & $109(14.9)$ & $440(16.9)$ & $151(12.8)$ & $416(15.6)$ & \\
\hline West & $4,340(45.7)$ & $1,019(44.0)$ & $327(44.6)$ & $1,141(43.9)$ & $592(50.0)$ & $1,261(47.4)$ & \\
\hline Area & & & & & & & .1979 \\
\hline Metropolitan & $8,053(84.9)$ & $1,948(84.0)$ & $624(85.0)$ & $2,186(84.2)$ & $1,000(84.5)$ & $2,295(86.3)$ & \\
\hline Urban & $1,267(13.4)$ & $325(14.0)$ & $95(12.9)$ & $366(14.1)$ & $154(13.0)$ & $327(12.3)$ & \\
\hline Rural & $1,171(1.8)$ & $45(1.9)$ & $15(2.0)$ & $45(1.7)$ & $29(2.5)$ & $37(1.4)$ & \\
\hline \multicolumn{2}{|c|}{ Charlson comorbidity index } & & & & & & $<.0001$ \\
\hline 0 & $5,653(60.0)$ & $1,034(45.6)$ & $407(55.5)$ & $1,547(59.8)$ & $774(65.5)$ & 1,891 (71.2) & \\
\hline 1 & $2,230(23.7)$ & $625(27.6)$ & $186(25.4)$ & $618(23.9)$ & $242(20.5)$ & $559(21.0)$ & \\
\hline 2 & $871(9.2)$ & $320(14.1)$ & $74(10.1)$ & $237(9.2)$ & $100(8.5)$ & $140(5.3)$ & \\
\hline$\geq 3$ & $670(7.1)$ & $288(12.7)$ & $66(9.0)$ & $184(7.1)$ & $65(5.5)$ & $67(2.5)$ & \\
\hline Stage & & & & & & & $<.0001$ \\
\hline III & $5,040(53.1)$ & $833(35.9)$ & $421(57.4)$ & $1,301(50.1)$ & $752(63.6)$ & $1,733(65.2)$ & \\
\hline IV & $4,451(46.9)$ & $1,485(64.1)$ & $313(42.6)$ & $1,296(49.9)$ & $431(36.4)$ & $926(34.8)$ & \\
\hline Grade & & & & & & & $<.0001$ \\
\hline Well differentiated & $177(1.9)$ & $31(1.3)$ & $22(3.0)$ & $47(1.8)$ & $31(2.6)$ & $46(1.7)$ & \\
\hline $\begin{array}{l}\text { Poorly } \\
\text { differentiated }\end{array}$ & $5,344(56.3)$ & $629(27.1)$ & $512(69.8)$ & $1,254(48.3)$ & $899(76.0)$ & $2,050(77.1)$ & \\
\hline Unknown & $3,970(41.8)$ & $1,658(71.5)$ & $200(27.3)$ & $1,296(49.9)$ & $253(21.4)$ & $563(21.2)$ & \\
\hline Histology type & & & & & & & $<.0001$ \\
\hline $\begin{array}{l}\text { Serous/ } \\
\text { adenocarcinoma }\end{array}$ & $6,984(73.6)$ & $1,353(58.4)$ & $520(70.8)$ & $2,026(78.0)$ & $932(78.8)$ & $2,153(81.0)$ & \\
\hline Mucinous & $328(3.5)$ & $86(3.7)$ & $60(8.2)$ & $90(3.5)$ & $42(3.6)$ & $50(1.9)$ & \\
\hline Endometrioid & $372(3.9)$ & $39(1.7)$ & $40(5.5)$ & $93(3.6)$ & $59(5.0)$ & $141(5.3)$ & \\
\hline Clear cell & $119(1.3)$ & $17(0.7)$ & $12(1.6)$ & $28(1.1)$ & $14(1.2)$ & $48(1.8)$ & \\
\hline Other epithelial & $1,688(17.8)$ & $823(35.5)$ & $102(13.9)$ & $136(13.9)$ & $136(11.5)$ & $267(10.0)$ & \\
\hline \multicolumn{2}{|c|}{ Complication within 30 days of surgery } & & & & & & $<.0001$ \\
\hline No complication & $1,655(36.2)$ & NA & $159(21.7)$ & NA & $350(29.6)$ & $1,146(43.1)$ & \\
\hline $\begin{array}{l}\text { Major } \\
\text { complications }^{b}\end{array}$ & $442(9.7)$ & NA & $78(10.6)$ & NA & $123(10.4)$ & $241(9.1)$ & \\
\hline $\begin{array}{l}\text { Minor } \\
\text { complications }^{b}\end{array}$ & $1,127(24.6)$ & NA & $121(16.5)$ & NA & $282(23.8)$ & $724(27.2)$ & \\
\hline $\begin{array}{l}\text { Major and minor } \\
\text { complications }\end{array}$ & $1,352(29.6)$ & NA & $376(51.2)$ & NA & $428(36.2)$ & $548(20.6)$ & \\
\hline
\end{tabular}

Abbreviation: NA, not available.

aCharlson comorbidity index calculated based on diagnosis claims made 12 months before and during the index month of diagnosis

bee supplemental eAppendix 1 for definitions of major and minor complications.

their therapy. In these patients, the cost of NCCN Guideline-consistent treatment was comparable to that of non-NCCN Guideline-consistent therapy with surgery and chemotherapy.

\section{Discussion}

This study was not intended to be a comparative effectiveness of treatment options but to assess the costs of various treatment strategies for the care of this chal- 


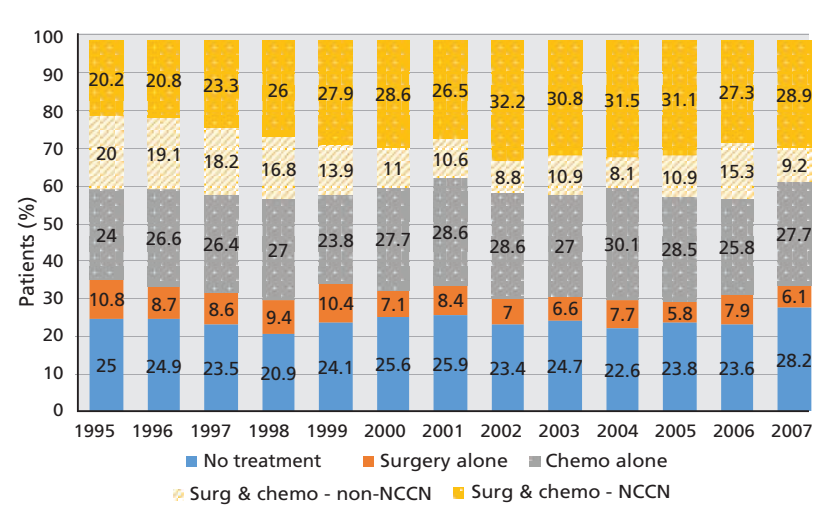

Figure 1. Patient distribution by treatment type and adherence to the NCCN Guidelines for Ovarian Cancer.

Abbreviations: chemo, chemotherapy; surg, surgery.

lenging disease. Ours is a first effort in understanding the distribution and variation of costs in ovarian cancer as we look at alternative payment strategies. ${ }^{2}$

Our study demonstrated that therapy that was consistent with NCCN Guidelines was comparable in cost with surgery and chemotherapy that was not consistent with guidelines. Given that therapy recommended by NCCN is associated with improved survival, ${ }^{20,21}$ this should serve as further stimulus to ensure that all patients with advanced ovarian cancer receive appropriate treatment. More than $70 \%$ of our cohort did not receive treatment that was concordant with NCCN Guidelines recommendations. Unfortunately, this is consistent with findings of 3 large population-based studies that have shown that more than $50 \%$ of patients did not have treatment that was consistent with national guidelines. ${ }^{12,20,21}$ Although there was a higher rate of patients who did not receive NCCN Guideline-concordant therapy in our cohort, our analysis was restricted to an older population, who had higher rates of receiving either no treatment or incomplete treatment. We did find that the proportion of patients receiving NCCN Guideline-consistent therapy increased over time.

We found that neoadjuvant chemotherapy and surgery, after adjusting for medical morbidity, was associated with a higher cost than primary surgery followed by chemotherapy. Our cohort is comparable to those in the studies by Forde et $\mathrm{al}^{6}$ and Poonawalla et $\mathrm{al}^{7}{ }^{7}$ who used the SEER-Medicare database for similar studies. Within the period of this analysis,

\begin{tabular}{|c|c|c|c|c|c|}
\hline \multirow[b]{2}{*}{ Treatment Type } & \multirow[b]{2}{*}{$\begin{array}{l}\text { Total \$US } \\
\text { (SD) }\end{array}$} & \multicolumn{2}{|c|}{ Inpatient } & \multicolumn{2}{|c|}{ Outpatient } \\
\hline & & $\begin{array}{l}\text { Cost of } \\
\text { Surgery, SUS } \\
\text { (SD) }\end{array}$ & $\begin{array}{l}\text { Other Inpatient } \\
\text { Costs, \$US } \\
\text { (SD) }\end{array}$ & $\begin{array}{l}\text { Cost of } \\
\text { Chemotherapy, } \\
\text { \$US } \\
\text { (SD) }\end{array}$ & $\begin{array}{l}\text { Other Outpatient } \\
\text { Costs, SUS } \\
\text { (SD) }\end{array}$ \\
\hline $\begin{array}{l}\text { No treatment } \\
(n=2,318)\end{array}$ & $\begin{array}{c}30,745 \\
(37,982)\end{array}$ & $\begin{array}{c}0 \\
(0)\end{array}$ & $\begin{array}{l}24,103 \\
(34,259)\end{array}$ & $\begin{array}{c}0 \\
(0)\end{array}$ & $\begin{array}{c}6,642 \\
(5,633)\end{array}$ \\
\hline $\begin{array}{l}\text { Surgery only } \\
(n=734)\end{array}$ & $\begin{array}{c}54,915 \\
(49,365)\end{array}$ & $\begin{array}{c}13,644 \\
(27,275)\end{array}$ & $\begin{array}{c}29,526 \\
(39,839)\end{array}$ & $\begin{array}{c}0 \\
(0)\end{array}$ & $\begin{array}{l}11,745 \\
(8,608)\end{array}$ \\
\hline $\begin{array}{l}\text { Chemotherapy only } \\
(n=2,597)\end{array}$ & $\begin{array}{c}69,255 \\
(39,858)\end{array}$ & $\begin{array}{c}0 \\
(0)\end{array}$ & $\begin{array}{c}33,290 \\
(31,896)\end{array}$ & $\begin{array}{c}19,683 \\
(18,474)\end{array}$ & $\begin{array}{l}16,282 \\
(9,718)\end{array}$ \\
\hline $\begin{array}{l}\text { Surgery and adjuvant } \\
\text { chemotherapy }(n=2,902)\end{array}$ & $\begin{array}{c}83,915 \\
(44,861)\end{array}$ & $\begin{array}{c}17,760 \\
(21,767)\end{array}$ & $\begin{array}{c}24,653 \\
(34,463)\end{array}$ & $\begin{array}{c}22,778 \\
(18,236)\end{array}$ & $\begin{array}{c}18,725 \\
(10,063)\end{array}$ \\
\hline $\begin{array}{l}\text { Neoadjuvant } \\
\text { chemotherapy } \\
(\mathrm{n}=940)\end{array}$ & $\begin{array}{c}96,360 \\
(42,103)\end{array}$ & $\begin{array}{c}20,810 \\
(14,676)\end{array}$ & $\begin{array}{c}26,540 \\
(30,856)\end{array}$ & $\begin{array}{c}28,036 \\
(20,161)\end{array}$ & $\begin{array}{c}20,974 \\
(10,349)\end{array}$ \\
\hline $\begin{array}{l}\text { NCCN Guideline- } \\
\text { consistent surgery and } \\
\text { chemotherapy } \\
(n=2,659)\end{array}$ & $\begin{array}{c}85,987 \\
(36,503)\end{array}$ & $\begin{array}{c}18,050 \\
(12,284)\end{array}$ & $\begin{array}{c}18,594 \\
(24,917)\end{array}$ & $\begin{array}{c}29,777 \\
(18,771)\end{array}$ & $\begin{array}{l}19,565 \\
(9,889)\end{array}$ \\
\hline $\begin{array}{l}\text { Non-NCCN Guideline- } \\
\text { consistent surgery and } \\
\text { chemotherapy } \\
(n=1,183)\end{array}$ & $\begin{array}{c}89,148 \\
(58,629)\end{array}$ & $\begin{array}{c}19,530 \\
(31,603)\end{array}$ & $\begin{array}{c}39,771 \\
(44,348)\end{array}$ & $\begin{array}{c}11,223 \\
(11,176)\end{array}$ & $\begin{array}{c}18,624 \\
(10,776)\end{array}$ \\
\hline
\end{tabular}

adjusted for year and geography. 
neoadjuvant chemotherapy was intentionally used as an alternative to standard therapy for patients with significant medical comorbidities and/or a poor performance status, both of which could account for higher cost. In addition, patients receiving neoadjuvant chemotherapy received significantly more chemotherapy than those receiving chemotherapy after surgery. This is comparable to prior findings ${ }^{22}$ and could also account for the differences in costs.

When evaluating the cost of care, focus should be paid to potentially modifiable factors that may impact cost without impacting the quality of care. The use of PET/CT was associated with significantly increased costs. It may be that PET/CT was a surrogate for either more-aggressive surveillance or platinumresistant disease, both of which may increase costs. However, neither the use of routine PET/CT nor the use of surveillance imaging have been found to be cost-effective, and neither is recommended. ${ }^{23}$ Treatment costs were significantly increased by surgical complications. This is consistent with previous findings ${ }^{24}$ and strengthens the need for predictive models to determine the most appropriate candidates for $\mathrm{cy}$ toreductive surgery. The 30-day surgical readmission rate in our study was greater than $30 \%$. Our results are similar to those of Eskander et $\mathrm{a}^{25}$ and call for additional research into reducing readmissions after surgery for ovarian cancer. ${ }^{26}$
An interesting finding was the decrease in outpatient costs after 2005 . This may reflect the availability of generic versions of paclitaxel in 2002, ${ }^{27}$ carboplatin in $2004,{ }^{28}$ and ondansetron in 2006. ${ }^{29}$ Although the priority is maintaining the quality of antineoplasic drugs, this highlights the impact of generic chemotherapy agents and supportive medications in reducing cancer costs. ${ }^{30}$ Although new costly biologic agents have been approved for use in ovarian cancer, in general they are not being used in upfront treatment, strengthening the applicability of our findings to patients with advanced ovarian cancer.

There are several limitations of this study. We did not have a control group for cost comparisons. Previous studies on cancer costs have used an agematched control group without cancer from SEERMedicare, ${ }^{31}$ or have calculated baseline health care costs. ${ }^{32}$ In addition, we could not identify only those interventions for which the sole indication was ovarian cancer; therefore, patients with multiple medical diagnoses may have higher disease-specific costs due to medical care that was not directed at cancer. Because we relied on codes specific to ovarian cancer in our analysis, our costs are reflective of the costs for the treatment of ovarian cancer in a real-life setting. With the use of a claims database, it is not possible to capture all indications for therapy or assess provider selection of therapy.

\section{Table 3. Adjusted Chemotherapy Costs in the Initial Period ${ }^{a}$}

\begin{tabular}{|c|c|c|c|c|c|c|c|}
\hline $\begin{array}{l}\text { Year of } \\
\text { Diagnosis }\end{array}$ & $\mathbf{N}$ & $\begin{array}{l}\text { Total Payments for } \\
\text { Chemotherapy }\end{array}$ & $\begin{array}{l}\text { Payments for } \\
\text { Facility }\end{array}$ & $\begin{array}{l}\text { Payments for } \\
\text { Providers }\end{array}$ & $\begin{array}{l}\text { Payments } \\
\text { Associated } \\
\text { With Platinum }\end{array}$ & $\begin{array}{l}\text { Payments } \\
\text { Associated } \\
\text { With Taxanes }\end{array}$ & $\begin{array}{l}\text { Payments } \\
\text { Associated } \\
\text { With Growth } \\
\text { Factor Support }\end{array}$ \\
\hline 1995 & 520 & 7,053 & 2,979 & 4,075 & 2,565 & 2,871 & 551 \\
\hline 1996 & 519 & 9,628 & 3,584 & 6,044 & 3,022 & 4,286 & 1,256 \\
\hline 1997 & 477 & 12,880 & 4,873 & 8,008 & 4,400 & 6,039 & 1,444 \\
\hline 1998 & 470 & 13,852 & 5,322 & 8,529 & 4,795 & 6,771 & 1,794 \\
\hline 1999 & 481 & 14,752 & 4,965 & 9,787 & 5,116 & 6,680 & 2,380 \\
\hline 2000 & 919 & 16,849 & 5,022 & 11,827 & 6,115 & 7,864 & 3,540 \\
\hline 2001 & 965 & 17,405 & 4,883 & 12,522 & 6,359 & 8,068 & 4,237 \\
\hline 2002 & 988 & 19,556 & 5,919 & 13,637 & 7,561 & 8,713 & 4,558 \\
\hline 2003 & 915 & 21,131 & 6,150 & 14,981 & 7,707 & 8,380 & 6,849 \\
\hline 2004 & 810 & 20,247 & 6,521 & 13,726 & 7,919 & 7,133 & 6,350 \\
\hline 2005 & 800 & 14,126 & 5,486 & 8,640 & 5,122 & 5,003 & 5,158 \\
\hline 2006 & 886 & 10,552 & 4,240 & 6,312 & 2,684 & 3,434 & 4,571 \\
\hline 2007 & 741 & 9,793 & 3,994 & 5,799 & 2,488 & 3,520 & 4,320 \\
\hline
\end{tabular}

${ }^{a}$ Adjusted for year and geography. 
Urban et al

Another limitation is related to the use of SEERMedicare data, as this data set only captures patients over the age of 65. From 2007 to 2011, the median age at ovarian cancer diagnosis in the United States was 63 years and approximately $54.6 \%$ of patients were younger than 65 years when diagnosed; the findings of our study may not reflect the experience of these younger patients. ${ }^{33}$ Older patients are projected to increase in number, ${ }^{34}$ which is why it is crucial to assess the costs of caring for these patients. We did not analyze patients enrolled in HMOs. The use of data from claims databases has the potential to introduce treatment misclassification. Prior studies have demonstrated a high level of agreement between Medicare data and chart review in the identification of surgery and chemotherapy, ${ }^{8,35}$ yet the accuracy of diagnostic codes is lower for comorbid conditions and treatment complications. ${ }^{36,37} \mathrm{We}$ were not able to capture charges related to intraperitoneal chemotherapy due the small number of patients who received this treatment. This is consistent with a prior study, which found that only $3.5 \%$ of women with stage III/IV chemotherapy from 2005 to 2009 received intraperitoneal chemotherapy. ${ }^{38}$

Our approach to estimating the costs of chemotherapy made it difficult to assess the cost difference of paclitaxel administered in a dose-dense fashion. ${ }^{39}$ Although other studies have used weeks of therapy to estimate cycles of chemotherapy, ${ }^{12,13}$ it may be that this estimation could have resulted in some inaccuracy. The SEER-Medicare data used was collected from 1995 to 2007. Although this is an older data set, the treatment strategy for advanced ovarian cancer has remained relatively consistent in the past 20 years, including both surgery and chemotherapy. We applied the definition of "NCCN Guidelineconsistent" therapy as being consistent with the guidelines issued in 2015 . These guidelines are similar to the first edition of the NCCN Guidelines for Ovarian Cancer, in which the optimal treatment for advanced ovarian cancer was surgery and chemotherapy with a platinum and taxane. ${ }^{40}$

\section{Conclusions}

Although the decision for a particular treatment of a patient with newly diagnosed ovarian cancer is an individual one, we must begin to understand the costs associated with various treatment strategies.
Understanding the variation in cost associated with the care of patients with advanced ovarian cancer may help identify areas in which additional clinical resources can be used to lower costs.

\section{Acknowledgments}

The authors gratefully acknowledge the support of the Marsha Rivkin Center for Ovarian Cancer Research.

\section{References}

1. Mariotto AB, Yabroff KR, Shao Y, et al. Projections of the cost of cancer care in the United States: 2010-2020. J Natl Cancer Inst 2011;103:117128.

2. American Society of Clinical Oncology. Potential approaches to sustainable, long-lasting payment reform in oncology. J Oncol Pract 2014;10:254-258

3. Kumar P, Moy B. Cancer health disparities and the cost of cancer care: payment model issues. J Natl Compr Canc Netw 2013;11:633-636.

4. Silber JH, Rosenbaum PR, Polsky D, et al. Does cancer treatment and survival differ by the specialty providing chemotherapy? J Clin Oncol 2007;25:1169-1175.

5. Sfakianos GP, Havrilesky LJ. A review of cost-effectiveness studies in ovarian cancer. Cancer Control 2011;18:59-64.

6. Forde GK, Chang J, Ziogas A, et al. Costs of treatment for elderly women with advanced ovarian cancer in a Medicare population. Gynecol Oncol 2015;137:479-484.

7. Poonawalla IB, Lairson DR, Chan W, et al. Cost-effectiveness of neoadjuvant chemotherapy versus primary surgery in elderly patients with advanced ovarian cancer. Value Health 2015;18:387-395.

8. Lairson DR, Parikh RC, Cormier JN, Du XL. Cost-utility analysis of platinum-based chemotherapy versus taxane and other regimens for ovarian cancer. Value Health 2014;17:34-42.

9. Warren JL, Klabunde CN, Schrag D, et al. Overview of the SEER-Medicare data: content, research, applications, and generalizability to the United States elderly population. Med Care 2002;40(8 Suppl):IV-3-18.

10. Deyo RA, Cherkin DC, Ciol MA. Adapting a clinical comorbidity index for use with ICD-9-CM administrative database. J Clin Epidemiol 1992;45:613-619.

11. Charlson ME, Pompei $\mathrm{P}$, Ales KL, et al. A new method of classifying prognostic comorbidity in longitudinal studies: development and validation. J Chronic Dis 1987;40:373-383

12. Griffiths RI, Barron RL, Gleeson ML, et al. Granulocyte-colony stimulating factor use and medical costs after initial adjuvant chemotherapy in older patients with early-stage breast cancer. Pharmacoeconomics 2012;30:103118.

13. Thrall MM, Gray HJ, Symons RG, et al. Trends in treatment of advanced epithelial ovarian cancer in the Medicare population. Gynecol Oncol 2011;122:100-106.

14. Earle CC, Schrag D, Neville BA, et al. Effect of surgeon specialty on processes of care and outcomes for ovarian cancer patients. J Natl Cancer Inst 2006;98:172-180.

15. Morgan RJ, Armstrong DK, Alvarez RD, et al. NCCN Clinical Practice Guidelines in Oncology: Ovarian Cancer. Version 1.2015. To view the most recent version of these guidelines, visit NCCN.org.

16. Brown ML, Riley GF, Schussler N, et al. Estimating health costs related to cancer treatment from SEER-Medicare data. Medical Care 2002;40(8 Suppl):IV-104-117.

17. Centers of Medicare \& Medicaid. Prospective Payment System Hospital Price. Available at: http://www.cms.gov/Research-Statistics-Data-andSystems/Statistics-Trends-and-Reports/MedicareProgramRatesStats/ MarketBasketData.html. Accessed March 16, 2016.

18. Centers of Medicare \& Medicaid. Addendum D: 2009 Geographic Adjustment Factors (GAFs). Available at: http://satro.org/2009\%20GAFs. pdf. Accessed March 14, 2016. 
19. Medicare Economic Index. Available at: http://www.cms.gov/ Research-Statistics-Data-and-Systems/Statistics-Trends-and-Reports/ MedicareProgramRatesStats/MarketBasketData.html.

20. Centers of Medicare \& Medicaid. Addendum E: 2009 CMS Geographic Practice Cost Indices (GPCIs) by state and Medicare locality. Available at: http://satro.org/2009\%20GPCIs.pdf. Accessed March 14, 2016.

21. Bristow RE, Powell MA, Al-Hammadie N, et al. Disparities in ovarian cancer care quality and survival according to race and socioeconomic status. J Natl Cancer Inst 2013;105:823-832.

22. Thrall MM, Gray HJ, Symons RG, et al. Neoadjuvant chemotherapy in the Medicare cohort with advanced ovarian cancer. Gynecol Oncol 2011;123:461-466.

23. Salani R, Backes FJ, Fung MF, et al. Posttreatment surveillance and diagnosis of recurrence in women with gynecologic malignancies: Society of Gynecologic Oncology recommendations. Am J Obstet Gynecol 2011;204:466-478.

24. Gordon LG, Scuffham PA, Beesley VL, et al. Medical costs and outcomes for Australian women with ovarian cancer: a patient-level analysis over 2.5 years. Int J Gynecol Cancer 2010;20:757-765.

25. Eskander RN, Chang J, Ziogas A et a. Evaluation of 30-day hospital readmission after surgery for advanced-stage ovarian cancer in a medical population. J Clin Oncol 2014;32:4113-4119.

26. Clark RM, Growdon WB, Wiechert A, et al. Patient, treatment and discharge factors associated with hospital readmission within 30 days after surgical cytoreduction for epithelial ovarian carcinoma. Gynecol Oncol 2013;130:407-410.

27. FDA Draft Guidance on Paclitaxel. Available at: http://www.fda.gov/ downloads/drugs/guidancecomplianceregulatoryinformation/guidances/ ucm320015.pdf. Accessed March 14, 2016.

28. ANDA Approval Reports: Approvals - June 2005. US Food and Drug Administration Web site. Available at: http://www.fda.gov/Drugs/ DevelopmentApprovalProcess/HowDrugsareDevelopedandApproved/ DrugandBiologic ApprovalReports/ANDAGenericDrugApprovals/ ucm062536. Accessed March 14, 2016.

29. FDA Approves First Generic Ondansetron Injection [press release]. US Food and Drug Administration Web site. Available at: http://www.fda.
gov/newsEvents/Newsroom/PressAnnouncements/2006/ucm108791.htm. Accessed March 14, 2016.

30. Renner L, Nkansah FA, Dodoo AN. The role of generic medicines and biosimilars in oncology in low-income countries. Ann Oncol 2013;24(Suppl 5):v29-32.

31. O'Neill CB, Atoria CL, O'Reilly EM, et al. Costs and trends in pancreatic cancer treatment. Cancer 2012;118:5132-5139.

32. Cipriano LE, Romanus D, Earle CC, et al. Lung cancer treatment costs, including patient responsibility, by disease stage and treatment modality, 1992 to 2003. Value Health 2011;14:41-52.

33. Howlader N, Noone AM, Krapcho M, et al. SEER Cancer Statistics Review, 1975-2011, National Cancer Institute. Bethesda, MD. Available at: http://seer.cancer.gov/csr/1975_2011/, based on November 2013 SEER data submission, posted to the SEER web site, April 2014. Accessed March $14,2016$.

34. United States Population Projections: 2000 to 2050. Available at: https:// www.census.gov/population/projections/files/analytical-document09.pdf. Accessed March 14, 2016.

35. Cooper GS, Virnig B, Klabunde CN, et al. Use of SEER-Medicare data for measuring cancer surgery. Med Care 2002;40(8 Suppl):IV-43-48.

36. Klabunde CN, Warren JL, Legler JM. Assessing comorbidity using claims data: an overview. Med Care 2002;40(8 Suppl):IV-26-35.

37. Potosky AL, Warren JL, Riedel ER, et al. Measuring complications of cancer treatment using the SEER-Medicare data. Med Care 2002;40(8 Suppl):IV-62-68.

38. Fairfield KM, Murray K, LaChance JA, et al. Intraperitoneal chemotherapy among women in the Medicare population with epithelial ovarian cancer. Gynecol Oncol 2014;134:473-477.

39. Katsumata N, Yasuda M, Takahashi F, et al. Dose-dense paclitaxel once a week in combination with carboplatin every 3 weeks for advanced ovarian cancer: a phase 3, open-label, randomized controlled trial. Lancet 2009;374:1331-1338.

40. Morgan RJ, Copeland L, Gershenson D, et al. NCCN Ovarian Cancer Practice Guidelines. The National Comprehensive Cancer Network. Oncology (Williston Park) 1996:10:293-310. To view the most recent version of these guidelines, visit NCCN.org. 